\title{
GCU
}

Glasgow Caledonian

University

University for the Common Good

\section{In search of parkrun tourism: destabilising contradictions or progressive conceptual tensions?}

McKendrick, John H.; Bowness, James; Tulle, Emmanuelle

Published in:

International Journal of Culture, Tourism, and Hospitality Research

DOI:

10.1108/IJCTHR-10-2019-0183

Publication date:

2020

Document Version

Author accepted manuscript

Link to publication in ResearchOnline

Citation for published version (Harvard):

McKendrick, JH, Bowness, J \& Tulle, E 2020, 'In search of parkrun tourism: destabilising contradictions or progressive conceptual tensions?', International Journal of Culture, Tourism, and Hospitality Research, vol. 14, no. 3, pp. 335-347. https://doi.org/10.1108/IJCTHR-10-2019-0183

\section{General rights}

Copyright and moral rights for the publications made accessible in the public portal are retained by the authors and/or other copyright owners and it is a condition of accessing publications that users recognise and abide by the legal requirements associated with these rights.

Take down policy

If you believe that this document breaches copyright please view our takedown policy at https://edshare.gcu.ac.uk/id/eprint/5179 for details of how to contact us. 


\section{In Search of Parkrun Tourism: Destabilising Contradictions or Progressive Conceptual Tensions?}

John H. McKendrick, James Bowness and Emmanuelle Tulle

Correspondance: jmke@gcu.ac.uk

McKendrick, J.H., Bowness, J. and Emmanuelle T. (2020) In Search of Parkrun Tourism: Destabilising Contradictions or Progressive Conceptual Tensions? International Journal of Culture, Hospitality and Tourism Management, Accepted for publication on May $1^{\text {st }}, 2020$, to be published in a forthcoming edition of the journal. DOI (10.1108/IJCTHR-10-2019-0183).

\section{Abstract}

This paper reflects on the nature of 'parkrun tourism' and the challenges this presents to our understanding of sports tourism. The contradictions and contested terrain of sports tourism is discussed with the reference to three of the most widely used definitions for the field. Parkrun tourism is introduced as comprising four formats, spanning the domestic and global, the informal and formal, the organic and institutional, and the experience and commercial product. The particular challenges that parkrun tourism presents to existing understandings of sports tourism is considered. The conclusion discusses the prospect of future research, both empirical and theoretical, on parkrun tourism. We outline a range of ways in which parkrun tourism affords opportunity for further inquiry for parkrun scholarship and sports tourism. A new specification for sports tourism is proposed that accommodates parkrun tourism.

\section{Keywords}

Parkrun; sports tourism; sport; tourism; recreational running;

\footnotetext{
Emerald has permitted us to published this Author Accepted Manuscript (AAM) under the Creative Commons Attribution Non-commercial International Licence 4.0 (CC BY-NC 4.0). Any reuse of this version of the paper is allowed in accordance with the terms outlined by the licence. To reuse the AAM for commercial purposes, permission should be sought by contacting permissions@emeraldinsight.com.

For the sake of clarity, commercial usage would be considered as, but not limited to:

o Copying or downloading AAMs for further distribution for a fee;

o Any use of the AAM in conjunction with advertising;

o Any use of the AAM by for promotional purposes by for-profit organisations;

o Any use that would confer monetary reward, commercial gain or commercial exploitation.
} 


\section{Parkrun: emergence of tourist potential}

Parkrun has humble origins as a collection of thirteen people gathering to run around Bushy Park in London on a Saturday morning in 2004 (Waterman, 2014). In little more than 15 years, in the UK alone, 30 million parkruns have been completed by 2.1 million registered users who may be taking part in one of over 650 weekly parkruns ${ }^{[i, i i]}$. Globally, in 21 nations across the continents of Europe, North America, Africa, Oceania and Asia, parkrun reports more than 4 million runners, 0.5 million volunteers, almost 2,000 events and more than 50 million runs $^{[i i i]}$. Comprising a timed $5 \mathrm{~km}$ run, and typically taking place within local parks, parkrun self-presents as a community, offering opportunities for free sporting activity, affording the possibility for health improvement or maintenance, while celebrating beginner and expert as equals. Offering an alternative to sedentary lifestyles ${ }^{[i v]}$ and the problems this presents (Thorpe et al., 2011), parkrun is positioned as facilitating physical activity for the private and public good.

An emerging body of empirical research, across a range of disciplines, has explored the broader significance of parkrun. Much of this work has engaged questions around the potential of parkrun as a public health intervention (Stevinson and Hickson, 2013, 2018, Stevinson et al., 2015; Haake, 2018; Haake et al., 2018; Wiltshire et al., 2018; Sharman et al., 2016), and its impact on wellbeing (Grunseit et al., 2018; Morris and Scott, 2019; Reece et al., 2019; Tulle et al., 2019). Others have explored parkrun and social injustice (Goyder et al., 2018; Schneider et al., 2019; Wiltshire and Stevinson, 2018), parkrun as a leisure space (Hindley, 2018), the social foundations of exercise participation in parkrun (Stevens et al., 2019), determinants of parkrun participation (Cleland et al., 2019), and volunteering within parkrun (Renfree and West, 2019).

Although conceived as being local and community-based, in early 2018, parkrun announced that the travel company Exodus had launched parkrun tourism[v]. At the same time, ideas of domestic parkrun tourism are promoted by parkrun LTD and independent groups of parkrunners. This paper adds to the extant literature 
by reflecting on the possibilities and tensions that are inherent in emergent concepts of the parkrun tourist. In seeking to accommodate parkrun tourism within the broader canon of knowledge on sports tourism, we challenge the contention of van Rhennan et al. $(2017,78)$, who when reflecting on the emergence of such specialist modes of sports tourism, assert that, “... the narrow focus on a particular type of activity may pose an analytical challenge to conceptual coherence more broadly". On the contrary, we posit the opposite conceptualising parkrun tourism has enabled us to strengthen the conceptual coherence of sports tourism: the emergence of this new practice has afforded an opportunity to re-appraise the wider field of which it is part. First, we introduce the ideas of parkrun tourism that have emerged within the parkrun community, finding that four distinct conceptualisations have resulted. We progress to reflect on the tensions and contradictions that these ideas of parkrun tourism present for parkrun. Next, we review the contested terrain of sports tourism; drawing on three of the most widely used definitions of the field, i.e. (Gibson, 1998; Standeven and de Knop, 1999; Gammon and Robinson, 2003). Developing the work of van Rhennan et al. (2017), we propose a conceptualisation of parkrun tourism that not only accommodates this with the wider field of sports tourism, but also strengthens its conceptual coherence.

\section{Four Faces of Parkrun Tourism}

In parkrunning circles, multiple notions of the parkrun tourist have emerged, spanning both global and domestic realms.

\section{The global parkrun tourist}

Global parkrun tourism is presented as a partnership between parkrun and one of their commercial sponsors, Exodus Travels [vi]. At the time of writing, Exodus was the only commercial travel company offering tourist packages with the explicit support of parkrun. This parkrun tourism is conceived as having two 
dimensions - it as a specific commercial product [vii] and it is a fusing together of kindred spirits [viii].

As a commercial product, Exodus Travels offer the opportunity to combine 'award-winning adventure' with participation in a parkrun in Poland (Krakow parkrun) and Namibia (Swakopmund parkrun); this is promoted on the websites of both parkrun and Exodus Travels. Furthermore, Exodus Travels highlight the possibility of extending an adventure holiday by flying in early to accommodate a parkrun in Italy (Florence parkrun) and other unspecified destinations. Others might consider this to be adventure tourism, although the interest in this paper is its significance as a mode of parkrun (sports) tourism.

As an alignment of interests and principles, parkrunners are encouraged to consider holidaying with Exodus Travels, which is incentivised with financial discounts, special offers and competitions. This alignment is multi-dimensional. For example, both parties highlight the other's 'community feel' and the sense of 'togetherness' that participation engenders. Both organisations draw parallels between the domestic (parkrun is described as a central hub for the local community) and the international (Exodus endeavouring to leave a positive and lasting impact of the communities visited). Exodus presents parkrun biographies for a number of its staff and stress that both parkrun and Exodus adventures have the potential to inspire friends and have a positive and lasting impact on participants. On the other hand, parkrun also describes both parties as inclusive movements that foster and continuously grow [their] community roots (emphasis added).

A second mode of global parkrun tourist with parallels to one mode of domestic parkrun tourism is considered below.

\section{The domestic parkrun tourist}

There are two popular conceptualisations of domestic parkrun tourist, one which promotes collections of sub-types of parkrun, the other which promotes 
the collection of as many parkruns as possible. Since the Spring of 2018, parkrun has maintained a blog on what it describes as the parkrun tourist series ${ }^{[\mathrm{ix}]}$. This comprises a series of 28 posts, which describe mini-collections of particular types of parkrun, with the invitation extended to visit each type. The series has identified many parkrun types, including those defined by the character of their route, quirks around hostnames, geographic location, as well as the landscapes through which they pass. Self-evidently, the parkrun tourist blog raises awareness of parkruns and encourages parkrunners to visit ones that are beyond their local community. Interestingly, the parkrun tourist was also identified as one of the key types of parkrunner in one blog, alongside PB chaser, statistic guru, milestone monster, dog runner, volunteer, buggy runner and 'others' $[\mathrm{x}]$. The focus of this type of parkrun tourist is centred on collecting a particular type of parkrun, which may align with other interests of the parkrunner.

Parkrun UK also shares information on 'those parkrunners who have attended at least twenty different parkrun events in the UK' [xi]. A global equivalent is also available for those who have attended at least thirty events (which should be considered a second type of global parkrun tourist] [xii]. By the start of September 2019, several thousand parkrunners were listed on the UK 'roll of honour' and, over 10,000 were listed for the global equivalent. Parkrun does not describe this as parkrun tourism. However, beyond parkrun, those whose parkrun experience is not limited to the local parkrun, are identified as parkrun tourists by both independent groups of parkrunners and Exodus Travels. These 'collectors of parkruns' are understood by Exodus to be 'part of the parkrun tourist movement, trying out different parkruns around the UK' [xii]. Furthermore, independent groups of parkrunners have established a UK parkrun tourist Facebook group (with over 5,000 members) [xiv], and a parkrun World Tourists groups (almost 800 members) ${ }^{[\mathrm{xv}]}$. 


\section{Contradictions or Creative Tensions for Parkrun and Sports Tourism?}

\section{Appraising the parkrun tourist}

There are differences among the four constructions of the parkrun tourist. First, although participating in a parkrun is a motivation for all four modes of parkrun tourism, it is less central to the global Exodus parkrun tourist; here, the parkrun is only one (and perhaps a subsidiary) element of a broader tourist package. Second, there are differences according to whether the parkrun tourist's focus is on quantity (the parkrun collectors) or quality (Exodus parkrun tourism focuses on experience) or quantity with quality (the variant of domestic parkrun tourist that is focused on collecting particular types of parkrun). Third, the endeavours of some parkrun tourists are celebrated as 'achievements' by parkrun LTD; the parkrun collectors are acknowledged by parkrun, with their achievement celebrated in the 'most events' list that is maintained. Fourth, the independence that is associated with parkrun participation (choose to participate if you will) contrasts with the tightly scheduled timetabling of parkrun participation in Exodus' parkrun product.

On the other hand, all modes of parkrun tourism encourage the parkrunner to seek experiences beyond the realm of the local and the familiar. Here, there may be a tension between the local orientation of parkrun (Sharman et al., 2019) and what tourism tends to imply, e.g. 'the local' is associated with the everyday, the familiar and low or no cost, whereas tourism is associated with the out-of-theordinary and necessarily higher expense. Indeed, it might be argued that there is a multiplicity of ways in which parkrun and tourism are contradictory, rather than complementary.

Firstly, parkrun valorises the familiar, of being part of a stable community of likeminded runners. In contrast, tourism implies the out of the ordinary, in its most adventurous forms joining unknown others who share the appetite for similar experiences. Secondly, parkrun is free and purportedly within reach of all, whereas tourism necessitates expense, and often presents as experiences that are beyond the means of many. Thirdly, parkrun is situated in everyday 
environments, whereas tourist locations are often attractive on account of being in out-of-the-ordinary locations. Finally, parkrun is recreational sport/physical activity, whereas sports tourism is more often than not, associated with competitive or professional sports and tourism more generally is often associated with what Stebbins (2014) refers to as 'casual' or 'project-based' leisure rather than the 'serious leisure' of sport. These contradictions mean the encouragement of the parkrunner as a tourist who collects experiences extending their community beyond the familiar of the everyday - might be viewed as a contradiction to the roots of parkrun.

Indeed, not only is the conception of parkrun tourism somewhat troubling to the origins of parkrun; it might be argued that parkrun tourism presents particular challenges to the concept of sports tourism. First, although most definitions of sports tourism acknowledge that the sports tourist can be participant, site visitor or event observer, the sports tourist as volunteer is marginal to ideas of sports tourism. Pigeassou (2004) is atypical in that he incorporates volunteering within a typology of sports tourism. Just as volunteering has featured much more prominently in the organisation of mega sports events in recent years (Doherty and Patil, 2019), so volunteering is central to parkrun, and celebrated by it [xvi]. Although parkrun volunteers are assumed to be local, there is no reason why this mode of sporting participation might be so restricted, and it is conceivable that the volunteer might 'collect' parkruns in much the same way as the runner. The possibility of the parkrun sport tourist who travels to participate as a volunteer is not accommodated within existing conceptualisations of sports tourism.

Second, parkrun is, at once, both a mass event and a low-key local event. In the UK, several thousand participate every week; however, this is across 650 events, with fifteen parkruns in the UK having a record attendance of fewer than fifty participants. Similarly, at once, parkrun is competitive and recreational, meeting the different needs of different participants. As a sporting event, it is unique and sits uncomfortably with the other sports that are central to thinking when ideas of sports tourism are being conceptualised and theorised. 
Third, as the proliferation of parkrun events continues apace [xvii] and the goal is to deliver a parkrun in every community that wants one [xviii], defining a parkrun tourist as someone who has participated in at least twenty different events becomes increasingly problematic for sports tourism. For example, there are now 56 events within the boundaries of Greater London alone, making it possible for many to acquire the status of parkrun tourist without leaving their city. Indeed, the Twitter hashtag \#LonDone is used to signify completion of all London parkruns. The implication - sometimes insistence - that sports tourism involves a break from the everyday, is inconsistent with this dominant notion of parkrun tourism within the parkrunning community.

\section{The Troubled Quest for Identity Within Sports Tourism}

Although sports tourism is now an established field of enquiry, with a sizeable body of scholarship built up over the last three decades (Higham and Hinch, 2018), its definition remains contested. Mokras-Grabowska $(2016,13)$ describes "terminological chaos in the literature ... [in which] terms are used interchangeably and the differences between them are not clear". The plurality of ideas of sports tourism led van Rheenen et al. $(2017,88)$ to undertake a systematic review of alternative definitions in the field, concluding that, "[a]s members of an international network of scholars and practitioners, we believe there remains a need to develop a working definition of sport tourism globally, with a set of agreed-upon criteria". van Rheenen et al. (2017) identified thirty distinct definitions of sports tourism noting that no single definition has gained primacy. On the other hand, in a carefully executed textual analysis, they identified five common parameters in definitions of sports tourism, two of which were included in the majority of definitions. They evidence that $90 \%$ of definitions contained reference to sport as the primary motivation and $70 \%$ made explicit reference to space. Also evident, although less prevalent, are references to time (37\%), participant experience (33\%) and economic considerations (13\%). No single definition embraced all five elements, although Pigeassou et al. (1999) and Standeven and de Knop (1999) included all but 
participant experience, and Pigeassou (2004) and Bouchet et al. (2004) included all but economic considerations. To highlight the inconsistencies across different understandings of sports tourism we focus on Gibson (1998), Standeven and de Knop (1999), and Gammon and Robinson (2003), each offering an established definition of sports tourism that continues to be among those most widely used by contemporary scholars.

Gibson (1998) suggests a defining feature of sports tourism is that trips must involve a change in everyday lifestyle. She then distinguishes between three types of sport tourism; active sports tourism (participation), events sports tourism (spectatorship) and nostalgia/sentimental/celebrity sports tourism (visitation of sports attractions). This latter mode overlaps with what has elsewhere been titled 'sport heritage tourism' (Ramshaw and Gammon, 2005). Gammon and Robinson (2003) distinguish 'sports tourism' (sport being the prime motivation to travel, with tourist activity as ancillary) from 'tourism sport' (tourism being the prime motivation for travel, with participating actively or passively, in competitive or recreational sport being a secondary activity). They further distinguish between hard and soft variants of each. Hard sports tourism is for active or passive participation in a competitive sporting event, whereas soft sports tourism is active recreational participation of a sporting/leisure nature. Hard tourism sport is participating, actively or passively, in competitive or recreational sport as a secondary activity. In contrast, soft tourism sport describes visitors who engage in some form of sport or leisure on an incidental basis. Unlike Gibson (1998) and Gammon and Robinson (2003), and as reported in Mokras-Grabowska $(2016,14)$, Standeven and de Knop (1999) do not differentiate between types, but rather provide an all-inclusive definition of sports tourism as being that involving, 'all forms of active and passive engagement in physical activity, both occasionally or regularly, which is undertaken for non-commercial or non-business purposes, and which requires travelling outside the place of permanent residence and work'.

There are some commonalities across these definitions. First, they all include active and passive participation, with Gibson (1998) further differentiating 
between watching events and visiting sites within the passive participation category. Second, they all include competitive and recreational sports, with Gammon and Robinson (2003) distinguishing these as sub-types using the descriptors 'hard' and 'soft'. Third, they are all motivation-based conceptualisations, with Gammon and Robinson (2003) distinguishing between types according to whether sport or tourism is the primary motivation for travel.

There are also some shared uncertainties. First, without a precise specification of a travel criterion, many forms of sporting activity could technically be classified as 'sports tourism' in each of these classifications, despite not being consistent with what would more generally be understood as sports tourism. For example, away-match travel in a local league meets all criteria of Standevan and de Knop (1999), is a clear example of where sport is the primary motivation to travel (Gammon and Robinson, 2003) and could be considered a change in everyday lifestyle for Gibson (1998). Second, it might be reasoned that all modes of sporting participation are within the realm of sports tourism in that they apply a break from the everyday world of work. However, this could be problematic given the nature of work for many, particularly those who can mould a working life around their sporting interests. Typically, a sporting activity might be considered to be sporting tourism if it takes place away from home. However, if those working away from home participate in sport in the evening in a pattern that is similar to their work/leisure balance at home (e.g. the recreational golfer 'collecting' new courses while working away from home in the summer, in a pattern that is similar to practising at the driving range after working hours in the winter) does this summer sport constitute a break from the everyday, thereby warranting inclusion as a form of sports tourism? More generally, communication technologies have effected a changing geography of workspace for many (Hubers et al., 2018), which undermines a strict division of work and leisure, which may problematise the possibility for some of defining consistently 'the everyday'.

There are also points of contention and apparent differences among these key definitions of sports tourism. First, Standevan and de Knop (1999) are alone in 
explicitly including regular travel; in contrast Gibson (1998) specifies the necessity of a break with the everyday, while Gammon and Robinson (2003) imply such a break. Therefore, there is ambiguity over the temporal frame. In terms of break with the everyday, it is unclear whether regular weekly, fortnightly or even monthly participation might be considered a break from the everyday. Similarly, if participation is seasonal, but regular within that season (e.g. a trip away for ice-climbing, every weekend in the winter) it is unclear whether this would constitute a break from the everyday.

Second, there is discord over the understanding of what constitutes sport for sports tourism. A central feature of Gammon and Robinson's (2003) classification is the distinction between competitive and recreational sport. In contrast, Standeven and de Knop (1999) focus on physical activity, and Gibson (1998) refers to sport but makes no distinction between types of sport. However, even if an agreement over what constitutes sport can be reached, the distinction between competitive and recreational sport can be problematic where a motivational based approach is used. Thus, both sporting events and independent sporting activity can be either recreational or competitive. To describe the fun-runner taking part in the London Marathon as taking part in competitive sport is a misnomer (which is an example of recreational activity in a competitive event); similarly, the club cyclist travelling to the Peak District to make the best use of good weather conditions in order to attempt to collect King of the Mountains for Strava segments (an example of competitive activity in a recreational ride) (Smith and Treem, 2017)

Finally, an unintended consequence of Gammon and Robinson's (2003) attempt to acknowledge the difference in whether the primary motivation for travel is for sport or tourism was to limit what is understood as sports tourism. By introducing the sub-categories of sports tourism (sport as primary focus) and tourism sports (tourism as primary focus), travel in which sport is not the primary focus is not considered to be sports tourism. This conception contrasts with the understanding promoted by Gibson (1998) and Standeven and de Knop (1999). Indeed, the insistence on a primary or secondary focus on sport also 
implies that a degree of non-sporting activity is required for a sporting activity to be considered sports tourism. In effect, a visit to Manchester to watch a test cricket series at Old Trafford would not be considered sports tourism, unless the visitor partook of some secondary 'tourist' activity.

As Mokras-Grabowska (2016) suggests and van Rheenan et al. (2017) demonstrate, there are many ways of understanding sports tourism. Our review of three of the most commonly used definitions highlights that there is also variation and ambiguity in understanding within the five parameters that van Rheenan et al. (2017) identify across alternative definitions of sports tourism. Drawing on these parameters, we move on to propose an inclusive definition and comprehensive classification of sports tourism that incorporates parkrun tourism.

\section{An Inclusive and Expansive Classification of Sports Tourists: Re-} conceptualising sports tourism through parkrun tourism

Our objective was to develop an inclusive classification of the sports tourist. To achieve this, we propose a multi-dimensional classification, which contrasts existing alternatives which include/exclude studies as sports tourism on the basis of limited range of criteria. We do not use the parameter of 'economic criterion' that according to van Rheenan et al. (2017) featured in almost one in seven of the original definitions of sports tourism that they reviewed. This reflects its relative insignificance to our particular focus on the sports tourist, rather than the wider business of sports tourism. Following van Rheenan et al. (2017), we propose that the sports tourist may be classified according to four dimensions, i.e. (i) motivations (exclusive motivation for non-professionals, primary motivation for non-professionals, secondary motivations for nonprofessionals, and for professional sportspeople who engage in non-professional sporting activity when 'working' away from home); (ii) whether or not it is event-based; (iii) whether or not the participant is an active sporting participant; and (iv) providing it conforms to a locational constraint, whether or not the visit 
involves an overnight stay. Together, these four planes of division result in thirty-two sub-types of sports tourist. Table 1 describes the sub-types and provides an example of parkrun tourism for each (shaded text in final column).

(insert Table 1 about here)

The examples in Table 1 are illustrative, rather than exclusive. However, it becomes clear that the popular conceptions of parkrun tourism that prevail among the wider parkrunning community do not align to a single mode in this typology. While it may be most apt to portray the sports tourism of domestic collectors of parkruns as being only motivated by sport, event-based, sporting participant and day-tripper (row 1 in the Table), it is plausible that some of their collecting might occur as part of a day-trip that is not exclusively given over to parkrunning (row 9), in an opportunistic manner when by chance a day's work away from home takes them to the vicinity of a parkrun (row 17), when on holiday in a location with a parkrun (row 18), or for each of the above, to complete a 'freedom' run ${ }^{\mathrm{xix}}$, as their visit does not co-incide with a formal parkun event (rows 5, 13, 21 and 22, respectively). Likewise, other formulations are possible for the only three popular notions of parkrun tourist that prevail in the parkrunning community: although the domestic collector of parkrun by type might be most likely to be motivated by sport, event-based, sporting participant and, depending on the parkrun location in relation to home, be either day-tripper (row 1) or overnight stayer (row 2); the global parkrun collector might be expected to be motivated by sport, event-based, sporting participant and overnight stayer (row 2); and the consumer of the global parkrun product is most likely to have sports as secondary motivation, be an overnight stayer, while also being an event based, sporting participant (row 18).

Location is central to our conceptualisation, and we provide a more precise specification than that which has been used in many definitions of sports tourism so far; we propose that to be considered sports tourism, it must involve participation in sport and a journey that necessitates either (i) an overnight stay away from home; (ii) a day-visit to partake of non-event based sporting activity 
that is beyond the local realm; or (iii) a day visit to participate in a local league or series that involves a leisure activity beyond travel and sporting participation and the immediate activities associated with each (e.g., respectively, such as stopping off en route to refuel (associated with travel) or post-match socialisation with opponents, before travelling home (associated with sporting participation). Given different cultural norms about what constitutes 'local' travel (Czepkiewicz et al., 2018), it is considered unhelpful to specify a precise distance for the boundary between local/non-local. Taken together, these specificity of these locational parameters avoid inclusion within sports tourism of what might be rightly viewed as regular sporting activity.

The temporal dimension has been a point of contention, with some definitions arguing that sports tourism necessitates an overnight stay. Our conceptualisation proposes that sports tourism need not necessarily include an overnight stay, acknowledging the importance of day-trips in domestic tourism (Allan et al., 2007).

Although sport motivation features prominently in definitions of sports tourism (Van Rheenan, 2017), there has been discord over what is included, with some arguing that sport is the only motivation, others that it can be the primary (rather than the exclusive) motivation, while others still accept that it can also be a secondary motivation to tourism. Our conceptualisation favours an inclusive approach that incorporates all of these. Providing that sport is a motivation, we find it useful to include as sports tourists those for whom sport in the only, the primary and a subsidiary motivation for the tourist trip. We also find it useful to highlight that when the professional sportsperson partakes of subsidiary sporting activity in addition to her/his work. It might reasonably be argued that this can be accommodated within 'sport as secondary motivation'. However, we find it useful to give prominence to this as the sports tourism of sports professionals is often explicitly omitted from definitions of sports tourism.

Increasingly less contentious is the acceptance that sporting tourism can be event-based and non-event based, and can involve sporting participants and 
non-participants. While it would be an over-statement to suggest that consensus has been reached on these points, it is certainly now a prevailing view.

The utility of our classification is drawn from its multi-dimensional framework and inclusive focus, which leads to an expansive understanding of the sports tourist. Although 32 categories is unwieldly, the objective is not to classify apart and to pursue a divisive understanding of the field. Rather, we provide a framework for better understanding the commonality across different forms of sports tourism; rather than undermining an overarching sense of sports tourism (van Rheenan et al., 2017), it is argued that this conceptualisation is well placed to identify the commonalities across what may appear different experiences of sports tourism. It also does not seek to undermine the utility of existing conceptualisations of tourism, but it nevertheless draws upon the wider base of knowledge in sports tourism to offer some critical appreciation. Specifically, for example, we would argue that there is merit in exploring ideas around the parkrun tourist as collector, while (with the benefit of Table 1), acknowledging that this collecting may take many forms beyond existing distinctions between domestic and global, and collectors by number, and by type.

\section{Conclusion: Empirical and Theoretical Directions for Parkrun Research}

With more than five million participants and over fifty million participations, our understanding of sports tourism must be able to accommodate parkrun, a sporting phenomenon that has grounds to support its grand claim of being a 'global sporting movement' (Fullagar, 2016). Regardless of whether the parkrun tourist is conceived as consumer of a commercial product; or a domestic/global collector focused on number, type or quirk, the emergence of parkrun tourism in the parkrun consciousness generates a rich empirical research agenda for sports tourism. What is the scale of parkrun tourism? To what extent can parkrun be used as part of the wider tourist offer? Does the promotion of parkrun tourism engender a re-evaluation of our understanding of places hitherto marginal to 
tourism? To what extent do domestic parkrun tourists constitute a collective? What are the demographic characteristics of those who comprise parkrun tourists? To what extent do parkrun tourists engage with parkruns post-run coffee culture? To what extent do parkrun regulars embrace parkrun tourists? Research could extend beyond the study of sports tourism and ask the following geographical questions: What is the geographical reach of domestic parkrun tourists? Is the parkrun tourist de-sensitised or hyper-sensitised to the landscapes through which they run? Does parkrun opens up spaces for leisure which hitherto women were less likely to use than men?

The emergence of parkrun also raises a rich vein of theoretical issues for scholars of sports tourism. For example, following Auge (1995), to what extent can we understand parkrun as creating a place from the non-place of a park as it takes on different meanings in the minds of parkrunners? Tzenelli's (2014) reflections on tourism in Rio around the Olympics as being an instrument of ideology and a means to exert power and control, resonates with those who view 'exercise as medicine' (of which parkrun is an exemplar) as having a neoliberal undercurrent premised on the individual's responsibility for managing health and well-being (Pullen and Malcolm, 2018). The extent to which parkrun constitutes the commodification of public space at the cost of the wider public for the gain of a private limited company should also be considered, given the controversies that have surrounded attempts made by some local authorities to be compensated for the hidden costs of parkrun (Darby, 2016). In what sense does parkrun constitute the 'global social movement' that it, and its supporters', assert? Is the notion of a social movement challenged when the benefit is conceived as being primarily private gain? Furthermore, while there would appear much alignment between the mobilities turn in social sciences and the emergence of parkrun (both challenging sedentarism; both concerned with the reimagining of the everyday as a meaningful landscape), it is questionable whether travelling to parkrun is conceived as more than the functional meansto-an-end that the mobilities turn seeks to challenge. 
However, the immediate purpose of this paper has been conceptual, appraising the concept of the parkrun tourist, extending the reach of parkrun scholarship to sports tourist studies, accommodating notions of parkrun tourism within the wider realm of sports tourism, and strengthening the conceptualisation of sports tourism as a result. Once simply a global sporting movement that was firmly rooted in community, in recent years the wider reach of parkrunners has been encouraged and promoted by commercial providers of adventure sport, parkrun LTD and informal groups of parkrunners. Accommodating parkrun tourism within the wider field of sports tourism has been the objective of this paper, achieved by the re-conceptualisation of the field to accommodate the challenges that parkrun presents.

\section{References}

Allan, G., Dunlop, S., \& Swales, K. (2007). The economic impact of regular season sporting competitions: the Glasgow Old Firm football spectators as sports tourists. Journal of Sport Tourism, 12(2), 63-97.

Augé, M. (1995), Non-places: An anthropology of supermodernity. John Howe, trans. New York, Verso.

Cleland, V., Nash, M., Sharman, M.J. and Claflin, S. (2019), "Exploring the HealthPromoting Potential of the "parkrun" Phenomenon: What Factors are Associated With Higher Levels of Participation?", American Journal of Health Promotion, Vol. 33 No.1, pp.13-23.

Czepkiewicz, M., Heinonen, J. and Ottelin, J. (2018), "Why do urbanites travel more than do others? A review of associations between urban form and long-distance leisure travel.", Environmental Research Letters, Vol. 13 No. 7, 073001.

Darby, M. (2016), "Why charging for parkrun is a terrible idea”, The Guardian, $13^{\text {th }}$ April, available at: https://www.theguardian.com/lifeandstyle/the-runningblog/2016/apr/13/why-charging-for-parkrun-is-a-terrible-idea

Doherty, A. and Patil, S. (2019), "Reflections on major sport event volunteer legacy research", Journal of Policy Research in Tourism, Leisure and Events, Vol. 11(sup1), s34-s42.

Fullagar, S. (2016), "Parkrun is an important movement-and should remain free for participants", The Conversation, April 25th, available at: 
https://theconversation.com/parkrun-is-an-important-movement-and-shouldremain-free-for-participants-58097

Gammon, S. and Robinson, T. (2003), "Sport and tourism: a conceptual framework", Journal of Sport Tourism, Vol. 8 No. 1, pp. 21-26.

Geffroy, V. (2017), “'Playing with space': a conceptual basis for investigating active sport tourism practices", Journal of Sport \& Tourism, Vol.21 No.2, pp.95-113.

Gibson, H. (1998), "Sport tourism: a critical analysis of research", Sport Management Review, Vol. 1, pp. 45-76.

Goyder, E., Lawrence, D., Bullas, A., Edmonds, C., Sabey, A., Taylor, M. and Potter, S. (2018), "Inequalities in participation in community physical activity events: The case of the five Sheffield parkrun", Journal of Physical Activity and Health. (Vol. 15, No. 10, pp. S89-S89).

Grunseit, A., Richards, J. and Merom, D. (2018.), "Running on a high: parkrun and personal well-being", BMC Public Health, Vol. 18 No. 1, p.59.

Haake, S., 2018. "Parkrun: a new model of physical activity for large populations?", The Sport and Exercise Scientist, 57, pp.18-19.

Haake, S., Kelley, J., Copeland, R. and Quirk, H., (2018), “The impact of parkrun on inactive populations in the UK". SHU Research Data Archive, http://doi.org/10.17032/shu-180001.

Hinch, T. and Higham, J.E.S. (2011), Sport Tourism Development, (2nd ed.). Bristol: Channel View Publications.

Higham, J., and Hinch, T. (2018). Sport Tourism Development. (3rd ed.). Clevedon: Channel View.

Hindley, D. (2018), "More than just a run in the park": An exploration of parkrun as a shared leisure space", Leisure Sciences, DOI: 10.1080/01490400.2017.1410741.

Hubers, C., Dijst, M., \& Schwanen, T. (2018), “The fragmented worker? ICTs, coping strategies and gender differences in the temporal and spatial fragmentation of paid labour', Time \& Society, Vol. 27 No. 1, pp.92-130.

Mokras-Grabowska, J. (2016), “Sports tourism: Terminological discussion”, Turyzm, Vol. 26 No.1, pp.13-18.

Morris, P. and Scott, H. (2019), "Not just a run in the park: a qualitative exploration of parkrun and mental health", Advances in Mental Health, Vol. 17 No.2, pp.110123.

Pigeassou, C. (2004), "Contribution to the definition of sport tourism", Journal of Sport \& Tourism, Vol.9 No. pp.287-289. 
Pullen, E. and Malcolm, D. (2018), "Assessing the side effects of the 'exercise pill': the paradox of physical activity health promotion", Qualitative Research in Sport, Exercise and Health, Vol. 10 No. 4, pp. 493-504.

Ramshaw, G., and Gammon, S. (2005), "More than just nostalgia? Exploring the heritage/sport tourism nexus", Journal of Sport Tourism, Vol. 10 No. 4, pp.229241.

Reece, L.J., Quirk, H., Wellington, C., Haake, S.J. and Wilson, F. (2019), “Bright spots, physical activity investments that work: Parkrun; a global initiative striving for healthier and happier communities", British Journal of Sports Medicine, Vol. 53 No. 6, pp.326-327.

Renfree, G. and West, J. (2019), "Differences in men and women volunteers within a parkrun environment", available at https://eprints.worc.ac.uk/8210/1/WISEAN\%20conf\%20poster Updated\%200 306 19.pdf (accessed 13 September 2019).

Schneider, P.P., Smith, R.A., Bullas, A.M., Bayley, T., Haake, S.S., Brennan, A. and Goyder, E. (2019), "Where should new parkrun events be located? Modelling the potential impact of 200 new events on socio-economic inequalities in access and participation", MedRxiv, p.19004143.

Sharman, M.J., Nash, M. and Cleland, V. (2019), "Health and broader community benefit of parkrun-An exploratory qualitative study", Health Promotion Journal of Australia, Vol. 30 No. 2, pp.163-171.

Smith, W.R. and Treem, J. (2017), "Striving to be king of mobile mountains: Communication and organizing through digital fitness technology", Communication Studies, Vol. 68 No. 2, pp.135-151.

Standeven, J. and de Knop, P. (1999), Sport Tourism, Human Kinetics, Illinois.

Stebbins, R. A. (2014). Careers in serious leisure: From dabbler to devotee in search of fulfilment. New York: Springer.

Stevens, M., Rees, T. and Polman, R. (2019), "Social identification, exercise participation, and positive exercise experiences: Evidence from parkrun", Journal of Sports Sciences, Vol. 37 No. 2, pp.221-228.

Stevinson, C., Wiltshire, G. and Hickson, M., (2015), "Facilitating participation in healthenhancing physical activity: a qualitative study of parkrun". International Journal of Behavioral Medicine, Vol. 22 No. 2, pp.170-177.

Stevinson, C., and Hickson, M. (2013), "Exploring the public health potential of a mass community participation event", Journal of Public Health, Vol. 36 No. 2, pp. 268274. 
Stevinson, C., and Hickson, M. (2018), "Changes in physical activity, weight and wellbeing outcomes among attendees of a weekly mass participation event: a prospective 12-month study", Journal of Public Health, fdy178, https://doi.org/10.1093/pubmed/fdy178.

Thorp, A.A., Owen, N., Neuhaus, M., and Dunstan, D.W. (2011). Sedentary behaviors and subsequent health outcomes in adults: a systematic review of longitudinal studies, 1996-2011. American journal of preventive medicine, 41(2), 207-215.

Tulle, E., McKendrick, J.H., \& Bowness, J. (2019), "Strava is from mars, parkrun is from venus: gendered experiences of running, well-being and Motivation", Mimeo.

Tzanelli, R. (2014), "Embodied art and aesthetic performativity in the London 2012 handover to Rio", Global Studies Journal, Vol. 6 No. 2, pp.13-24.

Van Rheenen, D., Cernaianu, S. and Sobry, C. (2017), “Defining sport tourism: a content analysis of an evolving epistemology", Journal of Sport \& Tourism, Vol. 21 No:2, pp.75-93.

Watterman, A. (2014), "The parkrun Story - Paul Sinton-Hewitt”, available at: https://blog.strava.com/the-parkrun-story-paul-sinton-hewitt-8943/ (accessed 13 September 2019)

Weed, M. (2005), "Sports Tourism Theory and Method-Concepts, Issues and Epistemologies", European Sport Management Quarterly, Vol.5 No.3, pp.229-242.

Wiltshire, G. and Stevinson, C. (2018), "Exploring the role of social capital in communitybased physical activity: qualitative insights from parkrun", Qualitative Research in Sport, Exercise and Health, Vol. 10 No.1, pp.47-62.

Wiltshire, G.R., Fullagar, S. and Stevinson, C. (2018), "Exploring parkrun as a social context for collective health practices: running with and against the moral imperatives of health responsibilisation". Sociology of Health \& Illness, Vol. 40 No. 1, pp.3-17. 
Table 1: Conceiving of the parkrun Tourist

\begin{tabular}{|c|c|c|c|c|c|}
\hline & $\begin{array}{l}\text { Sport } \\
\text { Motivation }\end{array}$ & $\begin{array}{l}\text { Event } \\
\text { status }\end{array}$ & $\begin{array}{l}\text { Participation } \\
\text { status }\end{array}$ & $\begin{array}{l}\text { Time-space } \\
\text { status }\end{array}$ & Parkrun Example \\
\hline$\frac{1 .}{2 .}$ & \multirow{6}{*}{$\begin{array}{l}\text { Sport as Only } \\
\text { Motivation }\end{array}$} & \multirow{3}{*}{$\begin{array}{l}\text { Event- } \\
\text { based }\end{array}$} & $\begin{array}{c}\text { Sporting } \\
\text { participant }\end{array}$ & $\begin{array}{c}\text { Day-trip } \\
\text { Overnight stay }\end{array}$ & Parkrun collector travels to a parkrun location, specifically to complete the parkrun at an event \\
\hline 3. & & & Non-sporting & Day-trip & \multirow{2}{*}{ Parkrun collector travels to a parkrun location, specifically to observe the parkrun event } \\
\hline 4. & & & participant & Overnight stay & \\
\hline 5. & & \multirow{3}{*}{$\begin{array}{l}\text { Not } \\
\text { Event- } \\
\text { based }\end{array}$} & $\begin{array}{c}\text { Sporting } \\
\text { participant }\end{array}$ & $\begin{array}{c}\text { Day-trip } \\
\text { Overnight stay } \\
\end{array}$ & $\begin{array}{l}\text { Parkrun collector travels to a parkrun location, specifically to complete the parkrun outside the } \\
\text { event (so-called 'freedom' run) }\end{array}$ \\
\hline 7. & & & Non-sporting & Day-trip & \multirow{2}{*}{$\begin{array}{l}\text { Parkrun collector travels to a parkrun location, specifically to visit the site of a historical parkrun } \\
\text { (e.g. Bushy Park, site of the first ever parkrun }\end{array}$} \\
\hline 8. & & & participant & Overnight stay & \\
\hline 9. & \multirow{8}{*}{$\begin{array}{l}\text { Sport as } \\
\text { Primary } \\
\text { Motivation }\end{array}$} & \multirow{4}{*}{$\begin{array}{l}\text { Event- } \\
\text { based }\end{array}$} & sporting & Day-trip & \multirow{2}{*}{$\begin{array}{l}\text { Parkrun collector travels to a parkrun location, specifically to complete the parkrun at an event, but } \\
\text { also chooses to spend time sightseeing before returning home. }\end{array}$} \\
\hline 10. & & & participant & Overnight stay & \\
\hline 11. & & & Non-sporting & Day-trip & \multirow{2}{*}{$\begin{array}{l}\text { Parkrun collector travels to a parkrun location, specifically to observe the parkrun event, but also } \\
\text { chooses to spend some time sightseeing. }\end{array}$} \\
\hline 12. & & & participant & Overnight stay & \\
\hline 13. & & \multirow{4}{*}{$\begin{array}{l}\text { Not } \\
\text { Event- } \\
\text { based }\end{array}$} & Spo & Day-trip & \multirow{2}{*}{$\begin{array}{l}\text { Parkrun collector travels to a parkrun location, specifically to complete the parkrun outside the } \\
\text { event (so-called 'freedom' run), but also chooses to spend time sightseeing before returning home. }\end{array}$} \\
\hline 14. & & & participant & Overnight stay & \\
\hline 15. & & & Non-sporting & Day-trip & \multirow{2}{*}{$\begin{array}{l}\text { Parkrun collector travels to a parkrun location, specifically to visit the site of a historical parkrun } \\
\text { (e.g. Bushy Park, site of the first ever parkrun), but also chooses to spend time sightseeing. }\end{array}$} \\
\hline 16. & & & par & Overni & \\
\hline 17. & \multirow{8}{*}{$\begin{array}{l}\text { Sport as } \\
\text { Secondary } \\
\text { Motivation }\end{array}$} & \multirow{4}{*}{$\begin{array}{l}\text { Event- } \\
\text { based }\end{array}$} & Sporting & Day-trip & \multirow{2}{*}{$\begin{array}{l}\text { While away from home for work/pleasure, a parkrunner participates in the local parkrun, as a } \\
\text { subsidiary part of the holiday experience. }\end{array}$} \\
\hline 18. & & & participant & Overnight stay & \\
\hline 19. & & & Non-sporting & Day-trip & \multirow{2}{*}{$\begin{array}{l}\text { While away from home for work/pleasure, a parkrunner attends to observe and support runners in } \\
\text { the local parkrun, as a subsidiary part of the holiday experience. }\end{array}$} \\
\hline 20. & & & part & Overn & \\
\hline 21. & & \multirow{4}{*}{$\begin{array}{l}\text { Not } \\
\text { Event- } \\
\text { based }\end{array}$} & Sporting & Day-trip & \multirow{2}{*}{$\begin{array}{l}\text { While away from home for work/pleasure, a parkrunner completes the route of a parkrun outside } \\
\text { the event (so-called 'freedom' run), as a subsidiary part of the short break experience }\end{array}$} \\
\hline 22. & & & participant & Overnight stay & \\
\hline 23. & & & Non-sporting & Day-trip & \multirow{2}{*}{$\begin{array}{l}\text { While away from home for work/pleasure, a parkrunner takes the opportunity to visit the site of the } \\
\text { local parkrun, perhaps given its particular features of the route. }\end{array}$} \\
\hline 24. & & & & Overnight stay & \\
\hline 25. & \multirow{7}{*}{$\begin{array}{c}\text { Non- } \\
\text { competitive } \\
\text { Sport as } \\
\text { Motivation of } \\
\text { Professional } \\
\text { Sportsperson }\end{array}$} & \multirow{4}{*}{$\begin{array}{l}\text { Event- } \\
\text { based }\end{array}$} & Sporting & Day-trip & \multirow{2}{*}{$\begin{array}{l}\text { While visiting a locale for the purpose of competing in professional sport, the sportsperson takes the } \\
\text { opportunity to complete the local parkrun. }\end{array}$} \\
\hline 26. & & & participant & Overnight stay & \\
\hline 27. & & & Non-sporting & Day-trip & \multirow{2}{*}{$\begin{array}{l}\text { While visiting a locale for the purpose of competing in professional sport, the sportsperson takes the } \\
\text { opportunity to observe and support runners in the local parkrun. }\end{array}$} \\
\hline 28. & & & participant & Overnight stay & \\
\hline 29. & & \multirow{3}{*}{$\begin{array}{l}\text { Not } \\
\text { Event- } \\
\text { based }\end{array}$} & & Day-trip & \multirow{2}{*}{$\begin{array}{l}\text { While visiting a locale for the purpose of competing in professional sport, the sportsperson takes the } \\
\text { opportunity to run around the route of the local parkrun (a freedom run, outside of a parkrun } \\
\text { event). }\end{array}$} \\
\hline 30. & & & participant & Overnight stay & \\
\hline 31. & & & $\begin{array}{l}\text { Non-sporting } \\
\text { participant }\end{array}$ & Day-trip & $\begin{array}{l}\text { While visiting a locale for the purpose of competing in professional sport, the sportsperson takes the } \\
\text { opportunity to visit the site of the local parkrun, perhaps given its historical importance (e.g. the site } \\
\text { of the first parkrun in that country). }\end{array}$ \\
\hline
\end{tabular}




\section{Notes}

i $\quad$ https://www.parkrun.org.uk/ (accessed 13 September 2019)

ii Throughout the paper, we report on parkrun evidence that has been published by parkrun and, to a lesser extent, Exodus Travels. We also draw on our awareness of debates on 'parkrun tourism' among the wider parkrun community. Our concern is with the presentation of parkrun tourism and parkrun and the narratives that are conveyed, rather than the veracity of the claims. Our interest arises from a larger project that explored well-being among Strava-using parkrunners (Tulle et al., 2018).

iii https://www.parkrun.com/ (accessed 13 September 2019)

iv https://blog.parkrun.com/au/2017/04/19/are-you-parkrun-smart/

v https://www.parkrun.org.uk/sponsors/exodus-travels/ (accessed 13 September 2019) vi $\quad$ https://www.parkrun.org.uk/sponsors/exodus-travels/(accessed 13 September 2019)

vii $\quad$ https://www.exodus.co.uk/insights/parkrun-tourism (accessed 13 September 2019)

vii $\quad$ https://www.exodus.co.uk/parkrun (accessed 13 September 2019)

ix https://blog.parkrun.com/uk/tag/parkrun-tourism-series/(accessed 13 September 2019)

x https://blog.parkrun.com/uk/2018/09/04/the-types-of-parkrunner/(accessed 13 September 2019)

xi $\quad$ https://www.parkrun.org.uk/results/mostevents/(accessed 13 September 2019)

xii https://www.parkrun.com/results/mostevents (accessed 13 September 2019) https://www.exodus.co.uk/insights/parkrun-tourism (accessed 13 September 2019) https://www.facebook.com/groups/UKparkrunTourists/ (accessed 13 September 2019) https://www.facebook.com/groups/408345396639301/ accessed 13 September 2019) https://support.parkrun.com/hc/en-us/articles/205762442-The-Volunteer-club (accessed 13 September 2019) https://www.parkrun.org.uk/results/historicalchart/ (accessed 13 September 2019)

xviii 'What next', https://www.parkrun.org.uk/ (accessed 13 September 2019)

Freedom runs, so-called by parkrun, are runs completed independently around parkun courses outwith parkrun events 